\title{
A CONTRIBUIÇÃO DOS ITALIANOS PARA A EDUCAÇÃO E A CULTURA BRASILEIRA
}

CENNI, F. Italianos no Brasil: “Andiamo in’Merica”. São Paulo: Ed. da EDUSP, 2011.

Resenhado por: Patricia Weiduschadt ${ }^{1}$

Renata Brião de Castro ${ }^{2}$

O livro "Italianos no Brasil: 'Andiamo in 'Merica"” foi reeditado em 2011. Com essa obra, o autor, Franco Cenni, recebeu o "Prêmio Itália". O livro está organizado em 15 blocos. No primeiro intitulado "Termos de um novo diálogo", o autor introduz o texto. Franco Cenni justifica a escrita do livro como uma forma de apresentar, ainda que de forma resumida, a história da imigração italiana no Brasil. Ainda que a primeira edição tenha sido editada há alguns anos, considera-se a relevância da obra para os pesquisadores da história da imigração italiana no Brasil, por se tratar de uma publicação que aborda as várias nuances da contribuição dos italianos na sociedade brasileira.

No capítulo "Quando havia caravanas e capitães de ventura", o autor escreve sobre as grandes navegações e os italianos que tiveram influência nos séculos XV e XVI, ainda sem entrar na especificidade do Brasil. No item "No tempo do império", o autor aborda a participação de alguns italianos em território brasileiro, como, por exemplo, Giuseppe Garibaldi.

No tópico "A colonização italiana no Rio Grande do Sul”, o autor faz um panorama da imigração nesse estado. Cenni descreve a instalação dos imigrantes no estado do RS, os primeiros anos da colonização, as casas dos italianos e a presença destes na indústria gaúcha. Neste capítulo, também se encontram dados do Anuário Estatístico do Rio Grande do Sul. Entre os dados elencados, encontra-se a porcentagem de italianos no RS, entre os anos de 1882 e 1914, os quais representavam 43\% dos imigrantes que chegaram ao estado.

No próximo capítulo, "Italianos nos estados", discute-se sobre os italianos nos demais estados do país: Rio de Janeiro, Paraná, Santa Catarina, Minas Gerais, Mato Grosso e nos estados da região norte do país.

O Estado de São Paulo encontra-se no capítulo: “O rei café e a grande imigração". Nesse tópico, o enfoque recai sobre a produção e a safra do café em São Paulo. São Paulo recebeu um grande número de imigrantes para trabalhar nas lavouras de café. Desta forma, a obra disserta sobre a chegada dos imigrantes ao estado. Um destaque relevante, nesta parte do texto, diz respeito à distinção entre a imigração e a colonização. A primeira diz respeito 


\section{Revista HIISTEYIDIR On-line}

à ida de pessoas para trabalhar nas lavouras, enquanto a segunda, (colonização) refere-se aos imigrantes que foram colonizar um lote de terra, normalmente em regiões com baixa ou nenhuma densidade populacional. Franco Cenni observa que a Itália transferiu para o Brasil, em menos de vinte anos, mais de um milhão de pessoas.

O próximo capítulo, intitulado "Evolução Industrial", refere-se à indústria e à contribuição dos italianos nesse setor. No item nomeado "Italianos, criadores de riquezas", apresentam-se as empresas oriundas deste grupo étnico e o ramo de atividade das respectivas empresas. A noção de prosperidade entre os italianos é abordada em outros autores. Conforme Corteze (2002), estabeleceu-se na historiografia que as dificuldades enfrentadas pelos imigrantes, tanto no transcurso da viagem quanto na chegada à colônia, foram superadas pelas qualidades excelentes dos imigrantes. Conforme a autora, consagrou-se na historiografia que as dificuldades enfrentadas pelos imigrantes, tanto no transcurso da viagem quanto na chegada à colônia, foram superadas pelas qualidades excelentes dos imigrantes. Ainda neste tópico é destacada a figura de Francisco Matarazzo, conforme Cenni, Matarazzo foi o italiano mais ligado ao progresso da indústria brasileira. $\mathrm{O}$ autor segue nos itens seguintes dissertando sobre os italianos e a relação com a economia. Assim, encontram-se números relativos aos estabelecimentos agrícolas pertencentes a estrangeiros, como, por exemplo, as principais propriedades rurais dos italianos distribuídas pelos diferentes estados brasileiros. A partir disso é possível notar que o Estado do Rio Grande do Sul é o que mais possuía propriedades rurais desta etnia. Fato explicável pelo fato da imigração no sul do país, ter se dado na forma de colonização.

$\mathrm{O}$ autor segue, nos itens seguintes, dissertando sobre os italianos e a relação com a economia. Elenca números relativos aos estabelecimentos agrícolas pertencentes a estrangeiros, as principais propriedades rurais dos italianos, distribuídas pelos diferentes estados brasileiros. Outro ponto destacado por Cenni refere-se aos estabelecimentos industriais pertencentes aos italianos no ano de 1920, num total de 2.119 estabelecimentos em todo o país.

O capítulo "O Passaporto Rosso" refere-se à chegada dos italianos ao Estado de São Paulo, a viagem da Itália até o Brasil, como eram os dias de viagem, a alimentação no navio, a chegada em terras brasileiras, onde ficaram acomodados, como eram distribuídos no estado. É interessante observar que a alimentação nos navios, conforme Cenni não era de boa qualidade. Outros estudos, como, por exemplo, os de Maestri (2000), mostram que a alimentação era farta e abundante. Esta discussão se torna interessante para a reflexão sobre a escrita da história a partir das fontes de pesquisa, do contexto em que se escreve e dos objetivos, pode-se ter diversificadas interpretações, o que torna o fazer historiográfico (CERTEAU, 1982) um processo vivo, dinâmico e dentro do contexto em que foi escrito.

Na sequência, a obra discorre sobre as instituições sociais, educativas e recreativas criadas por esse grupo étnico. Franco Cenni reforça a participação dos italianos no mercado 


\section{Revista HIIST'TEIDBR On-line}

jornaleiro de São Paulo. Ainda neste capítulo, são abordados os bairros italianos em São Paulo, entre eles, o Brás, o bairro italiano por excelência. Alguns dados do Anuário Demográfico do Estado de São Paulo, mostram o casamento entre grupos de etnias diferentes, assim como entre os italianos. Para o autor, o maior elemento de fusão entre os grupos étnicos é o casamento. Outro dado interessante de ser observado diz respeito ao tamanho da família italiana, a qual era formada por um grande número de pessoas. Dentro desta perspectiva, Luchese (2007) aponta a família como primeiro espaço de sociabilidade e afirma que esta, por sua vez, era numerosa e patriarcal.

As sociedades italianas também receberam atenção. A primeira surgiu no ano de 1854 na cidade do Rio de Janeiro, reunindo, nesse momento, 34 sócios. As sociedades esportivas também são referidas, embora o autor faça a ressalva de que essas existiam em menor número. Os imigrantes se ocuparam em organizar outras instituições como: hospitais, escolas e espaços de sociabilidade. Ainda referente à organização dos italianos, estes realizaram muitos congressos, por meio das sociedades. Esses congressos buscavam reunir todas as sociedades italianas do país, a fim de organizarem, em conjunto, suas demandas e ações.

As escolas italianas são também abordadas. As do meio urbano estiveram ligadas às Sociedades de Mútuo Socorro. Rech (2015) defende, em sua tese de doutorado, que muitas escolas étnicas italianas na cidade de Porto Alegre (RS) estiveram vinculadas às Sociedades de Mútuo Socorro. Conforme Cenni, o período de maior desenvolvimento das escolas italianas foi entre os anos de 1895 a 1919. Os estudos de Kreutz (2010) vão ao encontro dessa afirmação. O autor enfatiza que, no ano de 1930, o Brasil chegou a ter 2.500 escolas étnicas, das quais 396 eram italianas.

O capítulo "Agitadores de ideias" inicia-se com os periódicos redigidos em italiano no país. Ainda neste item, Cenni atribui aos italianos a organização sindical e as lutas pelas reinvindicações sociais no Brasil. No item "Ciência e cultura", referem-se à influência dos italianos no campo do direito e da medicina. Outrossim, há referências aos livreiros e à literatura, dando destaque ao fundador da Editora Globo, Giuseppe Bertaso, o qual era italiano. No campo da arte, escreve-se sobre alguns italianos ativos no movimento modernista, como, por exemplo, Anita Malfatti e Victor Brecheret.

No capítulo da "Arquitetura", descreve-se a atuação dos italianos nessa área. Neste tópico, é abordada, por exemplo, a influência dos arquitetos italianos na renovação da cidade do Rio de Janeiro. Outro exemplo é o projeto arquitetônico do Museu do Ipiranga (SP), atualmente Museu Paulista.

No capítulo "Teatro, música, pintura e escultura", abordam-se alguns artistas italianos, que, segundo o autor, não foram muitos os que desembarcaram no Brasil. Assim, são escassas as notícias em relação à atuação desses profissionais. Na sequência, no próximo capítulo: "Contribuição civilizadora, científica e cultural de religiosos", entre outros 
assuntos, o autor analisa aqui as influências de algumas ordens religiosas, como os capuchinhos e os salesianos no cenário brasileiro.

Por fim, no último capítulo intitulado "Da Primeira Guerra Mundial até nossos dias", debate-se a diminuição da imigração no país após a Primeira Guerra. Ainda, reflete-se sobre a fundação da Companhia Brasileira de Colonização e Imigração Italiana, no ano de 1950. Finalizando o capítulo e a obra, a abordagem centra-se na apresentação do Instituto Cultural ítalo-brasileiro. Este foi criado em 1948 e oferecia, inicialmente, cursos de ensino normal, e também cursos livres universitários.

O livro de Franco Cenni é uma obra bastante densa, com muitas informações sobre os italianos e sua inserção na sociedade brasileira. $\mathrm{O}$ autor especifica os diferentes segmentos nos quais os italianos tiveram influência, trazendo um panorama da movimentação deste grupo. Esta é uma das principais contribuições desse livro: elencar de forma abrangente, porém intensa, a presença do elemento italiano no Brasil. Ademais, o estudo pode servir como fonte, também, para pesquisadores interessados na temática, assim como para aqueles que apreciam a leitura sobre imigração italiana. Por se tratar de um estudo extenso e detalhado, torna-se uma das principais referências para os iniciantes na temática, pois, ao abordar de forma ampla a presença dos italianos no Brasil, o autor abre um leque de possibilidades para novas pesquisas.

\section{REFERÊNCIAS:}

CERTEAU, M. de. A escrita da história. Rio de Janeiro: Forense Universitária, 1982.

CORTEZE, D. P. Ulisses va in America: história, historiografia e mitos da imigração italiana no Rio Grande do Sul (1875-1914). Passo Fundo: Ed. da UPF, 2002.

KREUTZ, L. Escolas étnicas no Brasil e a formação do estado nacional: a nacionalização compulsória das escolas dos imigrantes (1937-1945). Poiésis, v. 3, n. 5, p. 71-84, 2010.

LUCHESE, T. Â. O processo escolar entre imigrantes na região colonial italiana do

Rio Grande do Sul, 1875 a 1930: leggere, scrivere e calcolare per essere alcuno nella vita. 2007. 495 f. Tese (Doutorado em Educação) - Universidade do Vale do Rio dos Sinos, São Leopoldo, 2007.

MAESTRI, M. Os Senhores da Serra: a colonização italiana no Rio Grande do Sul (1875 - 1914). Passo Fundo: Ed. da UPF, 2000.

RECH, G. L. Escolas étnicas italianas em Porto Alegre/RS (1877-1938): a formação de uma rede escolar e o fascismo. 2015. 451 f. Tese (Doutorado em Educação) -Universidade Federal de Pelotas, Pelotas, 2015. 


\section{Revista HIIS'TWIDBR (Dn-lime}

\section{Notas}

\footnotetext{
${ }^{1}$ Doutora em educação pela Universidade do Vale dos sinos - UNISINOS. Professora efetiva da universidade federal de Pelotas.

2 Doutoranda no Programa de Pós-Graduação em educação da Faculdade de educação da universidade Federal de Pelotas (PPGE/FaF/UFPel).
}

Submetido em: 03/09/2017

Aprovado em: 03/09/2017

Publicado em: 11/04/2018 